\title{
Modeling vaccination strategies to control white-nose syndrome in little brown bat colonies
}

\section{Eva Cornwell}

St.Olaf College, cornwe1@stolaf.edu

David Elzinga

University of Tennessee, Knoxville, delzinga@vols.utk.edu

Shelby R. Stowe

Colorado School of Mines, sstowe@mymail.mines.edu

See next page for additional authors

Follow this and additional works at: https://scholarscompass.vcu.edu/bamm

Part of the Dynamical Systems Commons, Immunity Commons, and the Population Biology Commons

https://scholarscompass.vcu.edu/bamm/2020/talk/21

This Event is brought to you for free and open access by the Dept. of Mathematics and Applied Mathematics at VCU Scholars Compass. It has been accepted for inclusion in Biology and Medicine Through Mathematics Conference by an authorized administrator of VCU Scholars Compass. For more information, please contact libcompass@vcu.edu. 


\section{Presenter Information}

Eva Cornwell, David Elzinga, Shelby R. Stowe, and Alex Capaldi 


\title{
Modeling vaccination strategies to control white-nose syndrome in little brown bat colonies
}

\author{
Eva Cornwell ${ }^{1}$, David C. Elzinga ${ }^{2}, *$, Shelby R. Stowe ${ }^{3}$, Alex Capaldi ${ }^{4}$ \\ ${ }^{1}$ Department of Mathematics, Statistics, and Computer Science, St. Olaf College, Northfield, MN 55057 \\ ${ }^{2}$ Department of Mathematics, University of Tennessee, Knoxville, TN 37996 \\ ${ }^{3}$ Department of Mathematics \& Statistics, Colorado School of Mines, Golden, CO 80401 \\ ${ }^{4}$ Department of Mathematics \& Statistics, Valparaiso University, Valparaiso, IN 46383 \\ * denotes speaker \\ delzinga@vols.utk.edu
}

Since 2006, the North American bat population has been in rapid decline due to white-nose syndrome (WNS), which is caused by an invasive fungus (Pseudogymnoascus destructans). The little brown bat (Myotis lucifugus) is the species most affected by this emerging disease. We consider how best to prevent local extinctions of this species using mathematical models. In 2017, development began on a new vaccine for WNS; we analyze the effects of implementing vaccination as a control measure. We create a SusceptibleExposed-Infectious-Vaccinated hybrid ordinary differential equation and difference equation model informed by the phenology of little brown bats. We compare the effectiveness of annual, biennial, and one-time vaccination programs for multiple durations of immunity length. We also determine the optimal time to vaccinate, if vaccinating only once, as a function of average duration of immunity. Next, we perform a sensitivity analysis to determine the robustness of our results. Finally, we consider other possible control measures together with vaccination to determine the optimal control strategy. We find that if the vaccine offers lifelong immunity, then it will be the most effective control measure considered thus far. 